\title{
Psychological Antecedents of Intentions to Participate in Last Chance Tourism: Considering Complementary Theories
}

\author{
Kyle Maurice Woosnam ${ }^{1,2}$, Manuel Alector Ribeiro ${ }^{3,2}$, Tara J. Denley ${ }^{1}$, Christ Hehir ${ }^{3}$, B. Bynum Boley ${ }^{1}$
}

\author{
${ }^{1}$ Park, Recreation and Tourism Management, Warnell School of Forestry and Natural Resources, University \\ of Georgia, Athens, GA, USA \\ ${ }^{2}$ School of Tourism \& Hospitality Management, University of Johannesburg, Auckland Park, South Africa \\ ${ }^{3}$ School of Hospitality and Tourism Management, University of Surrey, Guildford, Surrey, United Kingdom
}

Corresponding Author:

*Kyle Maurice Woosnam (Corresponding Author), Park, Recreation and Tourism Management, Warnell School of Forestry and Natural Resources, University of Georgia, 180 E. Green Street, Room 300, Athens, GA 30602, USA.

Email: woosnam@uga.edu

\begin{abstract}
Last chance tourism (LCT) has received significant attention within the academic literature and popular press due to its controversial nature of bringing travelers to threatened places. However, little theory has been applied to understand why travelers gravitate towards this controversial type of tourism. Hence, this work combines the value-belief-norm (VBN) model and theory of planned behavior (TPB) framework to explain intentions to participate in LCT. Survey data were collected from a national panel $(n=436)$ of U.S. travelers in 2019. A two-step modeling approach (CFA-SEM) was followed to examine psychometrics and hypothesized relationships between VBN constructs, TPB constructs and intentions to participate in LCT. Of the 11 hypotheses examined, 10 were supported, with both theories combining to explain $61 \%$ of the variance in travelers' intentions. The TPB construct of 'social norms' was the best predictor of LCT intentions, emphasizing the conspicuous nature of LCT's influence on demand.
\end{abstract}

Keywords: Value-belief-norm (VBN) model, theory of planned behavior, last chance tourism, structural equation modeling, national panel

This article should be cited as:

Woosnam, K. M., Ribeiro, M. A., Denley, T. J., Hehir, C., \& Boley, B. B. (2021). Psychological Antecedents of Intentions to Participate in Last Chance Tourism: Considering Complementary Theories. Journal of Travel Research. doi:10.1177/00472875211025097 


\section{Introduction}

It seems as though with each passing day, the only thing we can count on in life is change. The same can be said for tourism as destinations, residents, and travelers consider how to wrestle with uncertainties and change throughout society. One does not have to look far to find various news reports of climate change, overtourism, COVID-19, etc. to realize that the way the tourism industry operated ten years, five years, or even last year, is not the same. Assuming a somewhat stable return to normalcy in the way of travel in the near future, about which many authors have dissenting opinions, individuals will remain just as keen (if not keener), to travel to new places and forge experiences they will recollect for years to come-especially given the pent-up frustrations of being sequestered to their homes and the growing sense of urgency to visit some of our disappearing 'crown jewels' throughout the world (Brouder, Teoh, Salazar, Mostafanezhad, Pung, Lapointe, Desbiolles, Haywood, Hall, and Clausen 2020). As such, we, as researchers, find ourselves intrigued at learning more about this 'last chance tourism' (hereafter, LCT).

Definitions of LCT are rather straightforward and similar to many ecotourism definitions in the sense that both definitions encapsulate tourists' strong desires to visit unique natural environments around the world. Ballantyne, Packer, and Axelsen (2009) offered that the LCT phenomenon includes "tourists observing, photographing, and interacting with environments or individual species that may be endangered, threatened, or rare" ( $p$ 151). Acknowledging the importance of preservation from a social perspective, Lemelin, Dawson, Stewart, Maher, and Leuck (2010) adds that LCT involves "tourists explicitly seeking vanishing landscapes and disappearing natural and/or social heritage" (p 478).

Examples of LCT have been well documented in both the academic literature and popular media. Research has documented activities at risk due to climate change (Dawson, Johnston, Stewart, Lemieux, Lemelin, Maher and Grimwood 2011), including, diving in the Great Barrier Reef (Piggott-McKellar and McNamara 2017), polar bear viewing in Churchill (Groulx, Lemieux, Dawson, Stewart and Yudina 2016) and glacier viewing (Lemelin, Dawson and Stewart 2013). USA Today (an internationally distributed U.S. daily newspaper) included LCT as one of its 10 Best travel features. The author of the work (Cohen 2017) concluded that the Great Barrier Reef, Oceania (Maldives), Antarctica, Venice, Everglades, The Dead Sea, Madagascar, Mount Kilimanjaro, Glacier National Park and Machu Picchu were the 10BEST places to visit before they disappear.

Though intuitively, LCT may appear similar to ecotourism, the two are dissimilar in that the former does not explicitly emphasize sustainability (Lemelin et al 2010). This is evidenced in the work that calls into question the suitability of LCT (Dawson et al. 2011; Eijgelaar, Thaper and Peeters 2010). Further, the growing body of research on this special interest form of tourism is highlighted by ambiguity as to whether LCT is positive or negative.

Lemieux, Groulx, Halpenny, Stager, Dawson, Stewart, and Hvenegaard (2018) argue that such travel creates greater awareness of the issues certain environments and species are facing. Another positive is that LCT has actually been shown to be a beneficial force in contributing to greater sustainability of particular environments (Piggott-McKellar and McNamara 2017). On the flip-side, Büscher and Fletcher (2017) claim that a disconnect exists between visitors' travel to these places and the realization that they may be contributing to its demise. This is compounded by the fact that some see promoting LCT will only contribute to greater travel to the destination and ultimately, more impacts on these fragile environments (Dawson, Lemelin, Stewart, and Taillon 2015). Such mixed perspectives surrounding LCT beg the philosophical question of whether individuals should even participate in such travel as has been debated within the ecotourism literature (Krüger, 2005). The truth is that we need to advance research focusing on LCT in efforts to learn more about why people would consider participate in this niche form of travel (Denley, Woosnam, Ribeiro, Boley, Hehir, and Abrams 2020). Given the fact that research on the topic has moved into its second decade and we continue to find exploratory research focused on context-specific destinations, we need to shift towards conducting 
research that applies theory, so we can understand more about LCT and why travelers gravitate towards this controversial type of tourism. In fact, Fisher and Stewart (2019, p. 511) acknowledge that the "concept of LCT lacks theoretical underpinning." Lemelin and Whipp (2019) also alluded to fact that more theoretical advancements are imperative in moving this line of research forward.

In light of the need to move beyond mere context-specific studies on LCT and add theory to the understanding of why travelers gravitate towards this controversial type of tourism, this work employs two viable, well-established theoretical frameworks in an effort to explain individuals' likeliness of participating in LCT - the value-belief-norm (VBN) model and the theory of planned behavior. As such, the purpose of this research is to consider VBN constructs (i.e., personal values, environmental worldview, awareness of consequences, ascription of responsibility, and personal norms) and the theory of planned behavior constructs (i.e., perceived behavioral control, subjective norms, and attitudes concerning LCT) to explain individuals' likeliness of participating in LCT. Through this work, we will be able to better explain individuals' intentions to undertake last chance travel and the implications this may have for both theory and practice. In the way of the former, this work will provide a robust theoretical consideration of the psychological antecedents underpinning individuals' intentions to participate in LCT. As for the latter, findings from this research will inform marketing approaches of DMOs concerning the ideal travelers for this niche form of tourism, and ways destinations can harness this type of tourism into a force for good that brings awareness to environmental problems and leverages the tourism dollars associated with LCT to protect the very resources tourists are coming to see.

\section{Literature Review \\ Last Chance Tourism Research}

Most of the LCT research to date falls under one of two camps, either motivations of LCT travelers or perspectives of LCT destination stakeholders. Studies considering motivations of LCT travelers have found that species vulnerability from changes in climate (Dawson, Stewart, Lemelin, and Scott 2010) and feeling connected to iconic species in a vanishing ecosystem (Lemieux, et al., 2018) were key drivers in individuals visiting particular LCT destinations. Piggott-McKellar and McNamara (2017) went so far as to indicate that individuals with the strongest motivations to undertake LCT travel exhibited a significantly higher concern for the overall ecosystem health of a particular LCT destination in question.

Destination stakeholders' perspectives of LCT have also been examined within the literature. One such line of work has revealed a lack of residents' awareness that their community was considered an LCT destination (Dawson, Scott, and Stewart 2007; Olsen, Koster, and Youroukos 2012). Of course, many residents are aware of the fact that their town or community is considered an LCT destination. Liggett, McIntosh, Thompson, Storey, and Gilbert (2010) highlighted how some locals were bothered by the rapid expansion of infrastructure to accommodate tourists and the increased threats posed on the environment.

A special note on the extant research is that it is largely either contextually specific, focusing on LCT destinations such as Churchill, Manitoba or the Solomon Islands (which makes intuitive sense given the unique nature of LCT) (Dawson et al., 2015; Hindley and Font 2018; Lemelin and Whipp 2019) or exploratory in its research design (i.e., either qualitative or quantitatively descriptive in nature). What's more, minimal efforts have been made to ascertain individuals' intentions to participate in LCT or the cognitive antecedents that help to explain such intentions (see Denley et al. 2020). These cognitive antecedents are needed by researchers and destination managers to understand the underlying factors influencing travelers to gravitate towards this controversial type of tourism. Employing complimentary theoretical models such as the VBN and theory of planned behavior that embrace both psychological and social psychological mechanisms at work in contributing to individuals' intent to participate in LCT will no doubt be a sensible place to begin. 


\section{Value-Belief-Norm Model Situated in a Tourism Context}

The value-belief-norm (VBN) model was first developed by Stern, Dietz, Abel, Guagnano and Kalof (1999) based on core tenets from the values theory (Schwartz and Bilsky 1987), norm activation theory (Schwartz 1977), and the theoretical model of environmental concern (Stern, Dietz, and Guagnano 1995). The VBN, as Stern et al. (1999) proposed, highlights a linear causal model whereby personal values, environmental worldview, awareness of consequences, ascription of responsibility, personal norms, behavioral intentions, and behaviors are subsequently explained by the preceding construct. Despite a preponderance of empirical research employing the $\mathrm{VBN}$ has been undertaken in environmental psychology and environmental conservation literatures (owing to its origin within such fields), a growing body of work is unfolding within the travel and tourism literature (see Beall et al. 2020; Denley et al. 2020; Han, Hwang, and Lee 2017; Han, Olya, Cho, and Kim 2018; Landon, Woosnam, and Boley 2018; Lee and Jan 2018; Megeirhi, Woosnam, Ribeiro, Ramkissoon, and Denley 2020; Sharma and Gupta 2020).

The utility of the VBN model within the travel and tourism literature is highlighted though its application in numerous contexts (e.g., green hotel choice, ecotourism, cultural heritage preservation, last chance tourism, pro-environmental behavior, etc.). As such, notable findings have been provided linking the six original constructs formulated by Stern et al. (1999). Of the three value dimensions, altruistic and biospheric have been shown to significantly explain (in a positive direction) environmental worldview (Denley et al. 2020; Han et al. 2017; Landon et al. 2018; Lee and Jan 2018; Megeirhi et al. 2020; Sharma and Gupta 2020), as opposed to egoistic, which has less often served as a negative predictor of environmental worldview (Han et al. 2018; Megeirhi et al. 2020; Sharma and Gupta 2020).

Such an environmental worldview, as often measured through the New Ecological Paradigm (Dunlap, Van Liere, Mertig, and Jones 2000) has then served as a significant, positive predictor of awareness of consequences (Denley et al. 2020; Han et al. 2017; Han et al. 2018; Landon et al. 2018; Sharma and Gupta 2020). One's awareness of consequences then serve to positively explain ascription of responsibility (Denley et al. 2020; Han et al. 2018; Megeirhi et al. 2020; Sharma and Gupta 2020). These ascriptions or attributions have further been shown to account for personal norms (Denley et al. 2020; Han et al. 2018; Landon et al. 2018; Megeirhi et al. 2020; Sharma and Gupta 2020). Subsequently, an individual's personal norms have accounted for a significant degree of intentions to behave in a certain manner (Denley et al. 2020; Han et al. 2017; Han et al. 2018; Landon et al. 2018; Lee and Jan 2018; Megeirhi et al. 2020; Sharma and Gupta 2020). Though Stern et al. (1999) designed the VBN with intentional behaviors explaining actual behavior, most work has stopped shy of assessing this relationship. Given the empirical research that has successfully linked the six constructs within VBN models, the following five hypotheses (as reflected in Figure 1 below) are proposed:

$\mathrm{H}_{1 \mathrm{a}}$ : Egoistic values will be negatively related to an environmental worldview (as measured through the New Ecological Paradigm, NEP).

$\mathrm{H}_{1 \mathrm{~b}-1 \mathrm{c}}$ : Altruistic and biospheric values will be positively related to an environmental worldview (through NEP).

$\mathrm{H}_{2}$ : An environmental worldview (through NEP) will positively predict an awareness of consequences for participating in sustainable tourism.

$\mathrm{H}_{3}$ : Awareness of consequences will therefore be positively related to an ascription of responsibility for participating in sustainable tourism.

$\mathrm{H}_{4}$ : An ascription of responsibility will positively predict the degree of personal norms associated with sustainable tourism.

$\mathrm{H}_{5}$ : Personal norms will be positively related to an individuals' intentions to participate in LCT travel. 
The VBN however, may not be sufficient alone in explaining behavioral intentions (Beall et al. 2020; Denley et al. 2020; Tölkes 2020). In fact, the theory of planned behavior has been shown to compliment the VBN in serving to explain a more substantial degree of variance in behavioral intentions (Han 2015; LópezMosquera, and Sánchez 2012). As such, the current work will follow such a precedent in the context of LCT.

\section{Theory of Planned Behavior and Tourism Research}

The theory of planned behavior (TPB) has a lengthier history than the VBN, originating with the work by Ajzen (1991). Though much like the VBN, the TPB developed with a social psychology focus in mind. Core constructs within the framework are attitudes toward the behavior, perceived behavioral control, behavioral intentions, and behaviors. The former three serve to explain intentions, which then in turn, are proposed to explain behavior (Ajzen 1991). Though the TPB has been employed across a host of fields and disciplines (e.g., social psychology, psychology, environmental psychology, health care, environmental conservation, etc.), the framework has received considerable usage within the tourism literature, especially as of late (Ahmad et al. 2020; Eid, Agag, and Shehawy 2020; Erul, Woosnam, and McIntosh, 2020; Han 2015; Lee and Jan 2018; Meng, Chua, Ryu, and Han 2020).

Han (2015) found that attitudes about environmentally responsible behavior, subjective norms, and perceived behavioral control all significantly predicted (in a positive direction) intentions of individuals staying at green hotels to act in an environmentally responsible manner. Using a similar sample of participants, Eid et al. (2020) found that of the three antecedents to behavioral intentions, only attitudes and subjective norms (and not perceived behavioral control) positively predicted such intentions. Interestingly however, intentions did explain behavior (Eid et al. 2020). Among ecotourists, both Lee and Jan (2018) and Ahmad et al. (2020) revealed support for all three antecedents in explaining ecotourism behavioral intentions (in a positive direction), however, attitudes were the weakest predictors among the three. As Stern (2000) purported, the more involvement required to undertake the behavior in question, the less likely that attitudes will explain a significant degree of variance in the act. In the instance of last chance tourism (which involves extensive time and monetary commitments), attitudes may, in fact, be less salient than subjective norms and perceived behavioral control.

Jordan et al.'s (2018) application of the TPB breaks from these studies by separating attitudes into a two dimensional positive and negative attitudinal construct towards the destination of Cuba. The authors found that separating attitudes into two categories was beneficial because both positive and negative attitudes towards Cuba were influential over intent to visit across different time horizons. Considering volunteer tourists, Meng et al. (2020) demonstrated that attitudes, subjective norms, and perceived behavioral control all explained revisit intentions, with the latter construct serving as the weakest positive predictor. It should be noted that much like the VBN, many studies stopped shy of examining the relationship between behavioral intentions and actual behavior, despite Ajzen's (1991) original model including all five constructs. Based on significant relationships between the four constructs within research employing the theory of planned behavior, the following three hypotheses are advanced:

$\mathrm{H}_{6 a}$ : Positive attitudes about LCT will be positively related to an individuals' intentions to participate in LCT travel.

$\mathrm{H}_{6 \mathrm{~b}}$ : Negative attitudes about LCT will be negatively related to an individuals' intentions to participate in LCT travel.

$\mathrm{H}_{7}$ : Subjective norms concerning LCT travel will be positively related to an individuals' intentions to participate in LCT travel.

$\mathrm{H}_{8}$ : Perceived behavioral control focused on LCT travel will significantly predict the degree to which individuals intend to participate in LCT travel. 


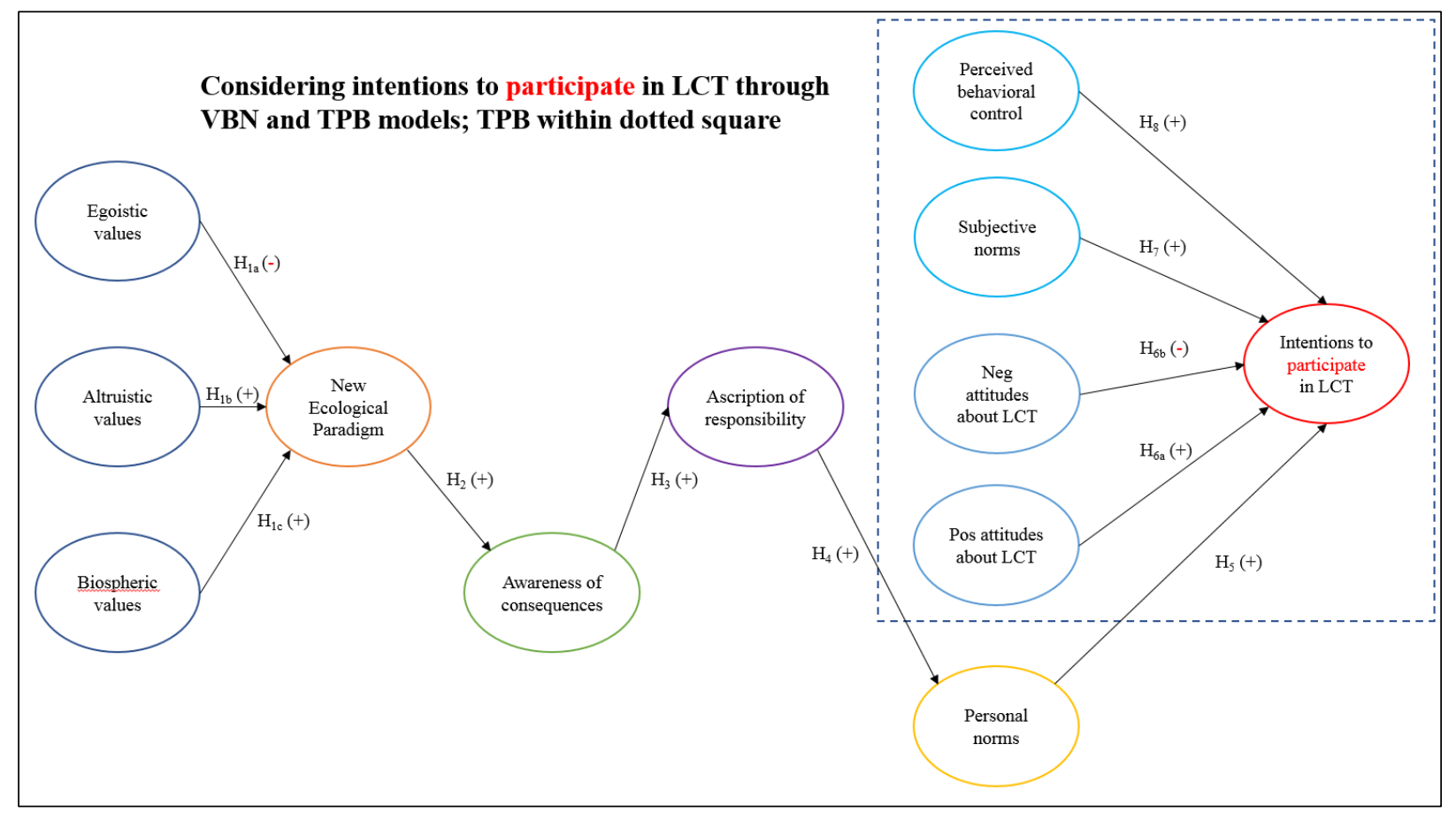

Figure 1. Conceptual model

Note: VBN constructs appear outside dotted rectangle; TPB constructs appear inside

\section{Methods}

\section{Data Collection and Sampling}

The population for this study consisted of U.S. citizens at least 18 years of age who had travelled within the last 12 months for leisure and whose annual household income was at least US $\$ 50,000$. This exclusionary threshold was chosen and deemed necessary to ensure the sample was reflective of the U.S. travel market, whereby individuals would have the necessary disposable income to travel to remote, international destinations, like those where LCT locations are found (Boley and Woosnam 2020). Based on these three criteria, a national panel of participants was secured through Amazon's Mechanical Turk (MTurk) using a self-administered questionnaire housed within the Qualtrics platform. An incentive to complete the questionnaire was offered in the form of monetary payment of $\$ 1$ as compensation for burden of time as well as a means to establish trust with participants (Dillman, Smyth and Christian 2014). Data were collected in July of 2019.

The utilization of a panel sample has become more widespread in the field of travel and tourism research due to numerous advantages, such as increased efficiency and minimal cost associated with data collection (Atzori, Fyall, and Miller 2018; Suess, Woosnam, and Erul 2020; Tasci and Milman 2019). A sampling approach of this nature through an online panel is considered acceptable and a reliable form of collection when the following two conditions are met: the inclusion coverage must be wide (i.e., employing a national panel) with well-detailed criterion (Vehovar, Toepoel, and Steinmetz 2016) and the sample size is robust (Babbie 2016). Additional support for this study's sampling methodology is evidenced by the emergence of several recent studies in the tourism field that have incorporated a similar panel sampling approach to test VBN models for their respective research (e.g., Denley et al. 2020; Han and Hwang 2017; Han, Hwang, and Lee 2017; Landon et al. 2018). Though limitations of MTurk have been advanced (e.g., small population size and potential overuse of MTurk) by Chandler, Rosenzweig, Moss, Robinson and Litman (2019), we used the 
platform given its ability to produce results comparable to other forms of data collection such as other online sample platforms, face-to-face, telephone, or mail methods (Bartneck, Duenser, Moltchanova and Zawieska 2015) and its continued acceptance within the travel and tourism literature (see Atzori et al. 2018; Denley et al. 2020; Tasci 2017; Zhang, Hou and Li 2020) based on cost effectiveness and ease of recruitment.

Five hundred eighty-one individuals accessed the survey via Amazon MTurk. Of those, 436 individuals completed the online survey (i.e., 75.0\% completion rate) housed within Qualtrics. Thirty cases were removed from analysis for those participants who either took less than six minutes (given the minimum completion time was gauged to be approximately six minutes) to complete the questionnaire or provided straight-line responses. Such an approach was undertaken following the works of Suess, Woosnam, Mody, Dogru, and Turk (2020) and Joo and Woosnam (2020) so as to help ensure the integrity and reliability of the data. Ultimately data analysis was carried out using the remaining 406 useable questionnaires.

\section{Measures}

The questionnaire developed for this study consisted of questions based on measures from prior research. Egoistic (three items), altruistic (three items), and biospheric (three items) values were adopted from the work of van Riper and Kyle (2014) and Landon et al. (2018) and measured on a 7-point Likert scale $(1=$ not all important and 7 = very important). Environmental worldview was measured using six items from the New Ecological Paradigm Scale (Dunlap et al. 2000) in accordance with the work of Landon et al. (2018). These items were presented on a 7 -point Likert scale $(1=$ strongly disagree; $7=$ strongly agree $)$. Five items, adopted from the work of van Riper and Kyle (2014), Raymond, Brown, and Robinson (2011), and Landon et al. (2018), were used to measure awareness of consequences. These items were presented using a 7-point Likert scale $(1=$ strongly disagree it is a problem; $7=$ strongly agree it is a problem), using the stem, "to what extent do you feel each of the following are problems created by travel and tourism." Ascription of responsibility was measured using three items on a 7-point Likert scale $(1=$ strongly disagree and $7=$ strongly agree $)$, adopted from based on the work of Steg and de Groot (2010) and Landon et al. (2018). Personal norms were measured using five items from the work of Landon et al. (2018), with items presented on a 7-point Likert scale $(1=$ strongly disagree and $7=$ strongly agree $)$.

Perceived behavioral control (five items), subjective norms (six items), and positive and negative attitudes toward visiting an LCT destination (16 items) were adapted from the Theory of Planned Behavior following the work of Jordan et al. (2018). Items were presented on a 7-point Likert scale $(1=$ strongly disagree; 7 = strongly agree). The last set of questions consisted of items measuring individuals' intention to participate in LCT (four items) and were adapted from the Intention to Visit scale (See and Goh 2019; Han et al. 2010). Respondents were asked to indicate their agreement with items pertaining to their intention to participate in LCT. Prior to responding to these items, respondents were presented with the following definition and examples of LCT.

"Last chance tourism describes tourists who are motivated to visit a particular place of interest to observe, photograph, or interact with environments or individual species that may be endangered or threatened because of the belief that it will either cease to exist, or may not be possible to visit in the future."

"Examples of last chance tourism destinations include but are not limited to the following:

Great Barrier Reef National Park (Australia) to see the reef before it dies.

Maldives (Indian Ocean) before rising sea levels submerge the island nation.

Glacier National Park (U.S.) to see the glaciers before they melt.

Endangered lowland min gorillas in Congo Basin (Africa) before they go extinct.

Dead Sea in Israel before it evaporates." 
Items measuring LCT intentions were recorded on a 7 -point Likert scale $(1=$ strongly disagree and $7=$ strongly agree). Finally, respondents provided responses to items concerning socio-demographic and economic status (e.g., age, gender, education, marital status, race, and ethnicity, annual household income, etc.).

\section{Data Analysis Strategy}

A two-step structural modeling approach was utilized to asses each of the 12 hypotheses proposed in the model (Anderson and Gerbing 1988). This included a confirmatory factor analysis (CFA) and structural equation modeling (SEM), both of which were conducted using AMOS v27. CFA confirmed the factor structures for all seven constructs included in the proposed model and examined the psychometric properties (i.e., reliability and validity estimates). Following the measurement model confirmation, a structural path model was developed and employed to test each of the model hypotheses.

Psychometrics for each factor within the model were assessed following the recommendations of Hair, Black, Babin, and Anderson (2019). Composite reliabilities were assessed to ensure that the estimates exceeded the threshold of 0.70 and that the average variance extracted (AVE) estimates were greater than 0.50 . Three forms of validity (i.e., convergent, discriminant, and nomological) were also assessed. Convergent validity is achieved when the following conditions are met: Standardized factor loadings are in excess of 0.50 ; corresponding $t$-values are significant; AVEs are greater than 0.50; and composite reliabilities are 0.70 or higher (Hair et al. 2019). Discriminant validity is established if the factor correlations are less than the square root of the AVEs (Hair et al. 2019).

Finally, nomological validity of the model was assessed through the testing of construct relationships. Model fit is deemed 'good' if TLI and CFI are > 0.90 and RMSEA and SRMR are < 0.07 (Hu and Bentler 1999). The fit of the measurement model and structural path model was assessed through the examination of

incremental model (i.e., Tucker-Lewis Index or TLI and comparative fit index or CFI) and absolute model (i.e., root mean square error of approximation or RMSEA and standardized root mean square residual or SRMR) fit indices.

\section{Results}

\section{Participant Profile}

Key observations from Table 1 can be drawn about sample participants. In terms of gender, a preponderance $(60.8 \%)$ identified as women. Slightly more than half of the sample (53.4\%) were under the age of 40 , with the average age of participants exactly at 40 years old. Most (65.9\%) were married. As far as education and income are concerned, 72.4\% had obtained at least a bachelor's degree while the median annual household income was between $\$ 75,000$ and $\$ 99,999$. A large majority $(81.5 \%)$ claimed to be White, with African Americans and Asian or Asian Americans comprising 8.9\% and 8.1\% of the sample, respectively. A small percentage $(6.2 \%)$ of individuals indicated they were Latin $n_{\mathrm{x}}$. In the way of recent travel, all individuals $(n=$ 405) had travelled within the U.S. during the previous 12 months. A high percentage (57.3\%) had travelled abroad during the same time period. Based on Qualtrics' recording of latitude and longitude figures of location where questionnaires were completed, 45 (of the 50) states within the U.S. were represented; $24.2 \%$ from states within the Northeast, 23.7\% from the Midwest, 26.9\% from the South, and 25.2\% from the West (Table 1).

Table 1. Participant profile 


\begin{tabular}{|c|c|c|}
\hline \multicolumn{3}{|l|}{ Gender $(n=406)$} \\
\hline Female & 247 & 60.8 \\
\hline Male & 155 & 38.2 \\
\hline Prefer not to answer & 4 & 1.0 \\
\hline \multicolumn{3}{|l|}{ Age $(n=401 ; M=40.33)$} \\
\hline $18-29$ & 60 & 15.0 \\
\hline $30-39$ & 154 & 38.4 \\
\hline $40-49$ & 109 & 27.2 \\
\hline $50-59$ & 51 & 12.7 \\
\hline$\geq 60$ & 27 & 6.7 \\
\hline \multicolumn{3}{|l|}{ Marital status $(n=405)$} \\
\hline Single & 116 & 28.6 \\
\hline Married & 267 & 65.9 \\
\hline Divorced/Separated & 20 & 4.9 \\
\hline Widowed & 2 & 0.5 \\
\hline \multicolumn{3}{|l|}{ Education level $(n=405 ;$ Median = Bachelor's degree $)$} \\
\hline Less than high school & 1 & 0.2 \\
\hline High school graduate & 13 & 3.2 \\
\hline Some college & 55 & 13.6 \\
\hline Technical/vocational/junior college graduate & 43 & 10.6 \\
\hline Bachelor's degree & 210 & 51.9 \\
\hline Graduate degree & 83 & 20.5 \\
\hline \multicolumn{3}{|l|}{ Race $(n=406)$} \\
\hline American Indian/Alaska Native & 4 & 1.0 \\
\hline Asian & 33 & 8.1 \\
\hline Black or African American & 36 & 8.9 \\
\hline Native Hawaiian or Pacific Islander & 2 & 0.5 \\
\hline White or Caucasian & 331 & 81.5 \\
\hline \multicolumn{3}{|l|}{$\operatorname{Latin}_{\mathrm{x}}(n=406)$} \\
\hline $\operatorname{Not}_{\text {Latin }} \mathrm{x}$ & 381 & 93.8 \\
\hline $\operatorname{Latin}_{\mathrm{x}}$ & 25 & 6.2 \\
\hline \multicolumn{3}{|l|}{ Annual household income $(n=406$; Median $=$ US\$75,000-99,999) } \\
\hline US\$50,000-74,999 & 178 & 43.8 \\
\hline US\$75,000-99,999 & 119 & 29.3 \\
\hline US\$100,000-199,999 & 101 & 24.9 \\
\hline US $\$ 200,000$ or more & 8 & 2.0 \\
\hline \multicolumn{3}{|c|}{ Region per U.S. Census Bureau designation ( $n=405 ; 45$ states covered except AK, ND, NH, NM, WY) } \\
\hline Northeast (CT, MA, ME, NJ, NY, PA, RI, VT) & 98 & 24.2 \\
\hline Midwest (KS, IA, IL, IN, MI, MN, MO, NE, OH, SD, WI) & 96 & 23.7 \\
\hline South (AL, AR, DE, FL, GA, KY, LA, MD, MS, NC, OK, SC, TN, TX, VA, WV) & 109 & 26.9 \\
\hline West (AZ, CA, CO, HI, ID, MT, NV OR, UT, WA) & 102 & 25.2 \\
\hline \multicolumn{3}{|l|}{ Travelled within the U.S. in the last 12 months $(n=405)$} \\
\hline No & 0 & 0.0 \\
\hline Yes & 405 & 100.0 \\
\hline \multicolumn{3}{|l|}{ Travelled outside of the U.S. in the last 12 months $(n=405)$} \\
\hline No & 173 & 42.7 \\
\hline Yes & 232 & 57.3 \\
\hline
\end{tabular}

\section{Measurement Model}

The measurement model was tested using confirmatory factor analysis (CFA). A model with 48 items and 12 factors fit the data satisfactory well with a significant $\chi^{2}$ value of 1854.023 that is known to be very sensitive 
to sample size. However, the normed $\chi^{2}$ (i.e., $\chi^{2} / d f=1.858$ ) was below the recommend threshold of 3.0 (Bagozzi and Yi 1988). The other fit indices were within the acceptable thresholds, with TLI $=0.932, \mathrm{CFI}=$ $0.940, \mathrm{RMSEA}=0.046$ and $\mathrm{SRMR}=0.054$. The measurement model was also tested for its psychometric properties. Reliability was examined using the recommendations proposed by Hair et al. (2019). As recommended, the Cronbach alpha $(\alpha)$ should be in excess of 0.70 for all the constructs (Hair et al. 2019). Also, the composite reliability (CR) and the average variance extracted (AVE) values for all constructs in the model should be greater than 0.70 and 0.50 respectively. All these criteria were met, providing evidence for the reliability of the measurement model, as summarized in Table 2. Validity was examined considering two forms of construct validity, convergent and discriminant. As shown in table 2, all factor loadings were above 0.50 , significant at $p<0.001$ and $t$-values were above the 1.96 threshold (Anderson and Gerbing 1988). Moreover, all AVE values were above the 0.50 threshold, thus providing support for convergent validity for all constructs (Fornell and Larcker 1981). Furthermore, the square roots of all AVEs (Table 3) were greater than the correlations between constructs, indicating that all constructs had discriminant validity (Fornell and Larcker 1981).

Lastly, to reduce the risks of common method bias or CMB (Jordan and Troth 2020), the Harman's single-factor test (Podsakoff, MacKenzie, Lee, and Podsakoff 2003) was performed to compare the CFA for the 12-factor measurement model with the single-factor model. As expected, the single-factor model yielded a poor fit $\left(\chi^{2}=9231.378 ; d f=1064 ; p<0.001 ; \mathrm{TLI}=0.390, \mathrm{CFI}=0.425 ; \mathrm{RMSEA}=0.175 ; \Delta \chi^{2}=7377.275\right.$; $\Delta d f=66 ; p<0.001)$ and was meaningfully worse than our proposed 12 -factor measurement model. This result indicated that the proposed 12-factor model performed much better than the single-factor model, demonstrating that $\mathrm{CMB}$ was not a pervasive issue within our data.

Table 2 at the end of the paper

Table 3. Discriminant validity

\begin{tabular}{|c|c|c|c|c|c|c|c|c|c|c|}
\hline Factors & $\begin{array}{l}\text { AVE } \\
10\end{array}$ & $\begin{array}{l}1 \\
11\end{array}$ & $\begin{array}{l}2 \\
12\end{array}$ & 3 & 4 & 5 & 6 & 7 & 8 & 9 \\
\hline 1. Egoistic values & 0.56 & 0.75 & & & & & & & & \\
\hline 2. Altruistic values & 0.61 & & -0.05 & 0.78 & & & & & & \\
\hline 3. Biospheric values & 0.66 & -0.03 & 0.67 & 0.81 & & & & & & \\
\hline 4. Environmental worldview (NEP) & 0.50 & -0.04 & 0.56 & 0.67 & 0.71 & & & & & \\
\hline 5. Awareness of consequences & 0.61 & 0.02 & 0.41 & 0.45 & 0.63 & 0.78 & & & & \\
\hline 6. Ascription of responsibility & 0.65 & -0.03 & 0.57 & 0.71 & 0.68 & 0.51 & 0.81 & & & \\
\hline 7. Personal norms & 0.69 & -0.10 & 0.54 & 0.68 & 0.66 & 0.47 & 0.64 & 0.83 & & \\
\hline 8. Positive attitudes about LCT & 0.62 & 0.13 & 0.22 & 0.13 & 0.08 & 0.02 & 0.09 & 0.14 & 0.79 & \\
\hline 9. Negative attitudes about LCT & 0.65 & -0.04 & 0.10 & 0.08 & 0.18 & 0.17 & 0.16 & 0.12 & -0.51 & 0.81 \\
\hline 10. Subjective norms & 0.66 & 0.33 & 0.15 & 0.17 & 0.07 & 0.09 & 0.09 & 0.12 & 0.38 & - \\
\hline 0.14 & 0.81 & & & & & & & & & \\
\hline 11. Perceived behavioral control & 0.65 & 0.06 & 0.06 & 0.12 & -0.05 & -0.04 & 0.04 & 0.07 & 0.13 & - \\
\hline 0.07 & 0.28 & 0.81 & & & & & & & & \\
\hline 12. Intentions to participate in LCT travel & 0.85 & 0.33 & 0.18 & 0.15 & 0.11 & 0.00 & 0.06 & 0.07 & 0.47 & - \\
\hline 0.15 & 0.73 & 0.31 & 0.92 & & & & & & & \\
\hline
\end{tabular}

AVE = average variance extracted

Note: Bolded diagonal estimates are square root of AVE; off-diagonal estimates are factor correlations

Note: All correlations are significant at the $p<0.001$ level 


\section{Structural Model and Hypotheses Testing}

In the second step of our analysis, we tested the structural relationships proposed in our model (Figure 1). Results demonstrated that the proposed model fit the data reasonably well $\left(\chi^{2}=2075.965, d f=1047, \chi^{2} / d f=\right.$ 1.983 , TLI $=0.922$, CFI $=0.928 ;$ RMSEA $=0.049$, and SRMR $=0.064)$. Results of the path analysis indicated that ten of the 11 hypotheses proposed were significant. First, the path relationships that test the effects within the VBN theory were assessed. The results show that the negative effect of egoistic values on environmental worldview through NEP $(\beta=-0.022, p>0.05)$ was insignificant, rejecting $\mathrm{H}_{1}$. Conversely, the effect of altruistic value $(\beta=0.224, p<0.001)$ and biospheric values $(\beta=0.593, p<0.001)$ on environmental worldview through NEP were both found to be positive and significant, thus supporting $\mathrm{H}_{1 \mathrm{~b}}$ and $\mathrm{H}_{1 \mathrm{c}}$. NEP was found to positively influence awareness of consequences $(\beta=0.639, p<0.001)$, supporting $\mathrm{H}_{2}$. The effect of awareness of consequences on ascription of responsibility $(\beta=0.639, p<0.001)$ was also significant, lending support to $\mathrm{H}_{3}$. Ascription of responsibility positively predicted the degree of personal norms associated with sustainable tourism $(\beta=0.949, p<0.001)$, providing support for $\mathrm{H}_{4}$. Personal norms were positively related to individuals' intentions to participate in LCT travel $(\beta=0.106, p<0.01)$, thus $\mathrm{H}_{5}$ was supported.

Additionally, the effects of the TPB constructs on LCT intention was also tested. Individuals' intentions to partcipate in LCT travel was positively predicted by positive attitudes about LCT $(\beta=0.269, p<0.001)$, and negatively predicted by negative attitudes about LCT $(\beta=-0.095, p<0.05)$. Therefore, providing support for $\mathrm{H}_{\mathrm{a}}$ and $\mathrm{H}_{\mathrm{b}}$ respectively. We also found support for $\mathrm{H}_{7}$ and $\mathrm{H}_{8}$, as individuals' intentions to participate in LCT travel was positively predicted by both subjective norms concerning LCT travel $(\beta=0.619, p<0.001)$, and perceived behavioral control focused on LCT travel $(\beta=0.344, p<0.001)$.

The model accounted for $48 \%, 45 \%, 30 \%, 89 \%$ and $61 \%$ of the variance in environmental worldview, awareness of consequences, ascription of responsibility, personal norms, and intentions to participate in LCT travel, respectively. Table 4 presents the results of the structural equation modeling. Taken together, the findings of this study provided evidence that the constructs comprising the two complementary theoretical frameworks, namely VBN and TPB, are useful determinants of individuals' intention to participate in LCT travel.

Table 4. Hypothesized relationships between constructs and observed relationships from the structural model

\begin{tabular}{llll}
\hline Standardized hypothesized relationship & $B$ & t-value & Results \\
\hline $\mathrm{H}_{1 \mathrm{a}}:$ Egoistic values $\rightarrow$ Environmental worldview (NEP) & -0.022 & $-0.487^{\text {ns }}$ & Not Supported \\
$\mathrm{H}_{1 \mathrm{~b}}$ : Altruistic values $\rightarrow$ Environmental worldview (NEP) & 0.224 & $3.316^{* * *}$ & Supported \\
$\mathrm{H}_{1 \mathrm{c}}$ : Biospheric values $\rightarrow$ Environmental worldview (NEP) & 0.593 & $8.292^{* * *}$ & Supported \\
$\mathrm{H}_{2}:$ NEP $\rightarrow$ Awareness of consequences & 0.639 & $11.006^{* * *}$ & Supported \\
$\mathrm{H}_{3}:$ Awareness of consequences $\rightarrow$ Ascription of responsibility & 0.545 & $10.400^{* * *}$ & Supported \\
$\mathrm{H}_{4}:$ Ascription of responsibility $\rightarrow$ Personal norms & 0.949 & $19.246^{* * *}$ & Supported \\
$\mathrm{H}_{5}:$ Perceived behavioral control $\rightarrow$ LCT intentions & 0.133 & $2.945^{* *}$ & Supported \\
$\mathrm{H}_{6 \mathrm{a}}:$ Positive attitudes about LCT $\rightarrow$ LCT intentions & 0.489 & $5.894^{* * *}$ & Supported \\
$\mathrm{H}_{6 \mathrm{~b}}:$ Negative attitudes about LCT $\rightarrow$ LCT intentions & -0.147 & $2.477^{*}$ & Supported \\
$\mathrm{H}_{7}:$ Subjective norms $\rightarrow$ LCT intentions & 0.694 & $14.270^{* * *}$ & Supported \\
$\mathrm{H}_{8}:$ Personal norms $\rightarrow$ LCT intentions & 0.192 & $3.555^{* *}$ & Supported \\
\hline
\end{tabular}

Note: $\mathrm{ns}=$ not significant; ${ }^{*} p<0.05 ;{ }^{* *} p<0.01 ;{ }^{* * *} p<0.001$.

Variance explained:

$R^{2}{ }_{\text {NEP }}=0.48$

$R^{2}{ }_{\mathrm{AC}}=0.45$

$R^{2}{ }_{\mathrm{AR}}=0.30$

$R^{2}{ }_{\mathrm{PN}}=0.89$

$R^{2}{ }_{\mathrm{LCT}}=0.61$ 


\section{Discussion and Implications}

The objective of this study was to better understand individuals' behavioral intentions to participate in LCT through the lens of two well-established theoretical frameworks, the VBN model and the TPB. Understanding individuals' intentions and behavior to travel to endangered places is a challenging and complex process. To understand why individuals travel to these places, we focused our efforts on a sequential model that used the constructs of the VBN model (i.e., personal values, environmental worldview, awareness of consequences, ascription of responsibility, and personal norms) and the TPB (i.e., perceived behavioral control, subjective norms, and attitudes concerning LCT) as a guide to identify the psychological determinants of individuals' likeliness to participate in such travel. The results indicated that except for egoistic values, the relationships within the VBN causal chain were all significant and found to predict individuals' intentions to participate in LCT, confirming results found by Denley et al. (2020). Moreover, these results demonstrated that each construct of VBN theory was significantly related to subsequent constructs further down the chain (i.e., environmental worldview $\rightarrow$ awareness of consequences; $\rightarrow$ ascription of responsibility; etc.), which is in keeping with the initial model advanced by Stern et al. (1995). Furthermore, these findings are congruent with previous studies that applied VBN theory to explain individuals' behavioral intentions in tourism studies confirming that each VBN construct is directly related to successive constructs in the model (Beall et al. 2020; Denley et al, 2020; Landon et al. 2018; Megeirhi et al. 2020).

Additionally, the present study tested the appropriateness of the four constructs under the TPB framework in explaining individual likeliness to travel to endangered places. The results demonstrated that the four constructs within the TPB framework are adequate determinants of intended travel for LCT. Perceived behavioral control, subjective norms and positive attitudes regarding LCT were found to significantly influence individuals' intention to participate in travel to endangered places. Conversely, negative attitudes about LCT negatively influenced individuals' likeliness to participate in travel to these fragile places. Overall, results of this study highlight that the proposed constructs encapsulated in these two theories were useful psychological determinants of why individuals want to participate in LCT travel to endangered places. Traveling to places that are in danger for some reason, may encourage travelers to connect with them and draw their own conclusions regarding their relationships between their values, beliefs, attitudes, norms and behavior towards these places (Denley et al. 2020; Stoner et al. 2014). As such, the use of VBN and TPB theories in tandem offer important theoretical and practical implications to consider as research concerning LCT travel continues to develop.

As echoed from the findings, the complementary use of the VBN and TPB frameworks (with their psychological antecedents) served to explain a robust degree of variance (nearly two-thirds) in individuals' intentions to participate in LCT. Such results are in line with what others have demonstrated in serving to explain intentions and behaviors of participating in various forms of travel (Han 2015; Han and Hyun 2017; Meng, et al. 2020). Among the five predictors of intentions, subjective norms had the greatest effect. Such a finding is not all together foreign as others (see Coon, van Riper, Morton, and Miller 2020; Jansson, Marell, and Nordlund 2010) have demonstrated similar results in their tested models. However, considered in relation to other model constructs - namely biospheric values, environmental worldview, awareness of consequences, ascription of responsibility, and personal norms - the salient role of subjective norms is somewhat contradictory. In essence, it raises the question of whether caring about what others think trumps deeply held values and beliefs about the environment so much so, that individuals would be willing to sacrifice the latter to visit LCT destinations.

A body of research has begun to investigate this very idea with Beall et al. (2020) finding that travelers were more influenced by the potential social return of positive social media posts from ecotourism experiences than their personal norms towards the environment. These types of findings provide credence to a long-held notion that tourism experiences can be used as a form of symbolic consumption (Dimanche and Samdahl 1994) 
and that tourists are motivated not only by their environmental beliefs and values but how their vacation will be viewed by their peers (Boley et al., 2018). While LCT may be viewed as unsustainable by some within academia (Büscher and Fletcher 2017; Dawson et al. 2015), it is possible that one's peer group either values the social prestige of going to these exotic destinations or they are agnostic to the negative impacts of this type of travel. Our complementary theoretical approach of combining the VBN with the TPB has helped unearth this finding, yet it creates a dilemma for sustainable tourism researchers. This blended theoretical perspective reveals that the demand for these types of LCT travels are multifaceted and more complicated than originally considered. Depending on what side of the fence one is about the positive or negative impacts of LCT, it will be hard to influence intention to participate or forgo LCT vacations because the antecedents are far-reaching and include not only personal environmental norms but travelers' attitudes towards LCT, the social desirability of LCT vacations, and the perceived ability for individuals to travel to LCT destinations.

By using the VBN and TPB theoretical frameworks, researchers are not the only ones who can identify psychological determinants of individuals' likeliness to participate in LCT; those within the tourism industry, through the application of the findings, also can. This study demonstrated that the VBN model and the four constructs within the TPB were significant in predicting individuals' intentions to participate in LCT. We suggest that this new knowledge can be beneficial for multiple stakeholders within the industry, including tour operators and destination management organizations (DMOs), by providing them with a deeper understanding of LCT and the tourists with whom want to participate in such travel.

Tour operators and destination managers should interpret these findings as suggesting LCT travelers are multi-faceted travelers influenced by not only their personal environmental norms but also the more traditional factors of the positive and negative aspects of the experience, the influence of their peers, and their own ability to successfully execute an LCT-type vacation. Tour operators can use these psychological determinants to tailor what experiences they add to their itineraries and offer to LCT tourists. The positive associations identified between higher altruistic and biospheric values and awareness of consequences for participating in sustainable tourism for example, suggest tourists may opt for more environmentally friendly/less carbon intensive activities while on their trip. For example, opting for a whale watching excursion onboard a hybrid-electric ship without noise or pollution (Brim Explorer 2020), might be more appealing to LCT tourists compared to a fossil-fueled alternative. The positive association between awareness of consequences and responsibility for participating in sustainable tourism can prompt DMOs to highlight and promote activities which have sustainability credentials. For example, Visit Tromso (2020) identifies Travel green activities which have been accredited by Visit Norway's Green Travel standard. Activities include the only Snowshoe Hike in the world that uses a Tesla Model X for its tour's transportation (Pukka Travels 2020). Moreover, by understanding the significance of norms of LCT tourists, and how these affect their behavior, DMOs and associations can gain confidence in the generation and implementation of visitor guidelines. By informing tourists from time-to-time that their behavior should line up with general norms within the context of visiting (e.g., by requesting tourists follow the guidelines such as the Association of Arctic Expedition Cruise Operators (AECO) Visitor Guidelines), destinations could ensure increased safety and greater preservation of their environments. This research suggests that if destinations, tour operators and non-profit organizations were to be in alignment, tourism could contribute to greater conservation rather than towards its demise.

Tour operators and DMOs of LCT destinations should also use these findings to support their traditional focus on the quality of the experienced offered as the positive and negative attitudes towards LCT were influential over intention to participate in LCT. While the sustainability of the offerings should not be disregarded, LCT tourists were found to be more influenced by their positive and negative evaluations of LCT offerings than their personal norms toward the environment. Relatedly, tour operators and DMOs should be cognizant of the social desirability of LCT offerings. The greater these LCT experiences are perceived by 
one's peers as of value, the more likely people will be to engage in them. This suggests tour operators and DMOs should have a strong presence on social media to help drive up the social desirability of their LCT offerings. It also suggests that tour operators and DMOs should carefully focus on the sustainability of their offerings since any public backlash towards LCT would likely diminish the social desirability of LCT reducing intention to visit. Lastly, LCT operators cannot ignore the financial costs and time constraints tourists face when considering an LCT vacation. Individuals' perceived control over taking a LCT vacation significantly influenced their intent to take vacations, implying that the greater the costs and travel constraints faced getting to the LCT destination, the less likely tourists will be to partake in LCT. There is not much LCT tour operators and DMOs can do to reduce the costs of international travel to these often-remote destinations, but they should be aware of any hurdles they control and work to ease these constraints. However, LCT tour operators and DMOs benefit from the 'loss aversion' mentality of LCT (Fisher and Stewart 2017), which combats any of these constraints by incentivizing travel now rather than later.

\section{Limitations and Future Research}

We would be remiss if we did not acknowledge limitations of our work. Our findings should be interpreted with some caution due to our focus specifically on U.S. citizens. Though the sample was rather inclusive of residents within the U.S., generalizability to other countries (especially those in the Global South) may be limited. Most likely, perspectives of LCT would be significantly different among individuals espousing Western and Eastern ideologies. That said, future research may help to shed light on potential differences in LCT perspectives (as well as VBN and TPB antecedents) across various cultures and countries.

Our sample was also derived from a panel including individuals who were paid for their participation. Though such an approach is growing in its employment (Atzori, Fyall, and Miller 2018; Suess, Woosnam, and Erul 2020; Tasci and Milman 2019), questions remain about truthfulness of responses and whether a sample truly mirrors the population under question. Not to say that panel data is inherently bad or flawed but future research should continue to question whether relying on data exclusively from panels is the best way forward. Until more research can be done on the utility of panel data, future research should consider using panel data in tandem with other forms of data secured from more traditional forms of survey data collection and qualitative interviews.

Erring on the side of including VBN and TPB constructs within our questionnaire, we neglected to ask participants if they had participated in prior LCT travel. Undoubtedly, prior experience could have served to explain intentions to participate in LCT in the future, as Chang, Backman, and Huang (2014) and Moon and Han (2018) have demonstrated within the travel and tourism literature. We implore future researchers to consider the role that prior experience may play in explaining future intentions to participate in LCT within subsequent models.

Though our work captures an increased variance explained in intentions to participate in LCT (over the work of Denley et al. 2020) by utilizing complementary theoretical models, our work does not explain actual LCT travel behavior. Others, who have combined the VBN and TPB within a tourism context, have acknowledged the same limitation, stopping short of explaining actual behavior (Han 2015; Meng et al. 2020). The most obvious way forward to rectify this shortcoming is to include actual behavior within subsequently proposed models. This of course is rather difficult given the temporal constraints of collecting data at various intervals so as to surmise intentions separately from actual behavior, though we implore future research to do just that. If, however, that is not possible, one alternative approach to provide a most robust picture of the link between behavioral intentions and actual behaviors (and predictors of each) is to employ fuzzy set qualitative comparative analysis (fsQCA) as Eid et al. (2020) has most recently done.

Despite our intentions to further the area of research concerning LCT utilizing a theoretical approach,

this work only considers two theoretical frameworks. As LCT research progresses, we suggest additional 
studies employ the utilization of different theories. Lemelin and Whipp (2019) argue that greater theoretical development and testing are crucial in the continued advancement of LCT research. One only has to scour recent articles within the tourism literature to find great potential theories. For instance, complexity theory (as recently employed by Mehran and Olya 2020) may help to shed light on the complex cognitive and affective aspects contributing to participation in LCT travel. Considering the role that motivations play in participating in LCT travel, another theory to consider may be self-determination theory (as recently utilized by Zhang, Cole, Ricci, and Gao 2019). Assuming actual behavior is measured, future research may also consider cognitive appraisal theory (as recently used by Choi and Choi 2019) to explain how LCT experiences among travelers elicit emotions (both positively and negatively). We hope this work will serve as a springboard forward so that researchers may continue to grapple with the paradoxical nature of LCT in this time of great uncertainty for travel.

Finally, the data were collected prior to the global COVID-19 pandemic in which we currently find ourselves. Therefore, our results should be interpreted with this in mind. If this study were repeated at this point in time, would similar results be found? Due to isolation and social distancing, individuals may be even more aware of their values, norms, attitudes, and beliefs given the time they have had to potentially reflect on these self-perceptions. If that is the case, our findings may just be 'the tip of the iceberg.' Prior to COVID-19, many LCT destinations were not nearly as overrun with tourists as places centred on mass tourism; far fewer tourists can be found in either destination type now. Though these LCT destinations are experiencing somewhat of a reprieve from tourism, many potential travellers anxiously await the day when they can freely travel once more. At that time, will pent-up desires to travel to see some of the last remaining cultural and natural vestiges be heightened? Only time will tell as we continue to live in unprecedented times and await the dust to settle.

\section{References}

Ahmad, W., W.G. Kim, Z. Anwer, and W. Zhuang. 2020. "Schwartz Personal Values, Theory of Planned Behavior and Environmental Consciousness: How Tourists' Visiting Intentions towards Eco-friendly Destinations are Shaped?" Journal of Business Research, 110: 228-236.

Ajzen, I. 1991. "The Theory of Planned Behavior." Organizational Behavior and Human Decision Processes, 50(2): 179-211.

Anderson, J.C., and D.W. Gerbing. 1988. "Structural Equation Modeling in Practice: A Review and Recommended Two-step Approach.” Psychological Bulletin, 103(3): 411.

Association of Arctic Expedition Cruise Operators (AECO). 2020. "Visitor guidelines." Retrieved on November 20, 2020 from https://www.aeco.no/guidelines/visitor-guidelines/

Atzori, R., A. Fyall, and G. Miller. 2018. "Tourist Responses to Climate Change: Potential Impacts and Adaptation in Florida's Coastal Destinations." Tourism Management, 69: 12-22.

Babbie, E. 2016. The Practice of Social Research. (14 ${ }^{\text {th }}$ Ed.). Cengage.

Bagozzi, R.P., and Y. Yi. 1988. "On the evaluation of structural equation models." Journal of the Academy of Marketing Science 16(1): 74-94.

Ballantyne, R., J. Packer, and M. Axelsen. 2009. "Trends in Tourism Research." Annals of Tourism Research, 36(1): 149-152.

Bartneck, C., A. Duenser, E. Moltchanova, and K. Zawieska. 2015. “Comparing the Similarity of Responses Received from Studies in Amazon's Mechanical Turk to Studies Conducted Online and with Direct Recruitment. PloS one, 10(4): e0121595. 
Beall, J.M., B.B. Boley, A.C. Landon, and K.M. Woosnam. 2020. "What Drives Ecotourism: Environmental Values or Symbolic Conspicuous Consumption?” Journal of Sustainable Tourism, doi/full/10.1080/09669582.2020.1825458

Boley, B.B. and K.M. Woosnam. 2020. "Going Global or Going Local? Why Travelers Choose Franchise and Independent Accommodations." Journal of Travel Research. doi/full/10.1177/0047287520904786

Boley, B.B., E.J. Jordan, C. Kline, and W. Knollenberg. 2018. "Social Return and Intent to Travel." Tourism Management, 64: 119-128.

Brim Explorer. 2020. "The ships.” Retrieved on November 20, 2020 from https://brimexplorer.com/the-boats

Brouder, P., S. Teoh, N.B. Salazar, M. Mostafanezhad, J.M. Pung, D. Lapointe, F. Higgins Desbiolles, M. Haywood, C.M. Hall and H.B. Clausen. 2020. "Reflections and Discussions: Tourism Matters in the New Normal post COVID-19." Tourism Geographies, 22(3): 735-746.

Büscher, B. and R. Fletcher. 2017. "Destructive Creation: Capital Accumulation and the Structural Violence of Tourism." Journal of Sustainable Tourism, 25(5): 651-667.

Chandler, J., C. Rosenzweig, A.J. Moss, J. Robinson, \& L. Litman. 2019. “Online Panels in Social Science Research: Expanding Sampling Methods beyond Mechanical Turk. Behavior Research Methods, 51(5): 2022-2038.

Chang, L., K.F. Backman, and Y.C. Huang. 2014. "Creative Tourism: A Preliminary Examination of Creative Tourists' Motivation, Experience, Perceived Value and Revisit Intention." International Journal of Culture, Tourism and Hospitality Research, 8(4), 401-419.

Choi, H., and H.C. Choi. 2019. "Investigating Tourists' Fun-eliciting Process toward Tourism Destination Sites: An Application of Cognitive Appraisal Theory." Journal of Travel Research, 58(5): 732-744.

Cohen, B. 2017. "Last-chance Tourism: People are Flocking to these Destinations Before They Disappear." USA Today. Retrieved on April 23, 2021 from https://www.10best.com/interests/explore/last-chancetourism-people-flocking-to-destinations-before-they-disappear/

Coon, J.J., C.J. van Riper, L.W. Morton, and J.R. Miller. 2020. "What Drives Private Landowner Decisions? Exploring Non-native Grass Management in the Eastern Great Plains." Journal of Environmental Management, 276, https://doi.org/10.1016/j.jenvman.2020.111355

Dawson, J., M.J. Johnston, E.J. Stewart, C.J. Lemieux, R.H. Lemelin, P.T. Maher, and B.S.R. Grimwood. 2011. "Ethical Considerations of Last Chance Tourism." Journal of Ecotourism, 10(3): 250-265.

Dawson, J., R.H. Lemelin, E.J. Stewart, and J. Taillon. 2015. "Last Chance Tourism: A Race to be the Last." In M. Hughes, D. Weaver, and C. Pforr (eds.), The practice of sustainable tourism: Resolving the paradox (pp. 133-145). London: Routledge.

Dawson, J., D. Scott, and E.J. Stewart. 2007 (November). "Climate Change Vulnerability of the Polar Bear Viewing Industry in Churchill, Manitoba, Canada." In Proceedings of the international conference on tourism and global change in polar regions, Oulu, Finland (Vol. 29, pp. 18-23).

Dawson, J., E.J. Stewart, H. Lemelin, and D. Scott. 2010. "The Carbon Cost of Polar Bear Viewing Tourism in Churchill, Canada.” Journal of Sustainable Tourism, 18(3): 319-336.

Denley, T.J., K.M. Woosnam, K.M, M.A. Ribeiro, B.B. Boley, C. Hehir, and J. Abrams. 2020. "Individuals' Intentions to Engage in Last Chance Tourism: Applying the Value-Belief-Norm Model." Journal of Sustainable Tourism, 28(11): 1860-1881.

Dillman, D.A., J.D. Smyth, and L.M. Christian. 2014. Internet, Phone, Mail, and Mixed-Mode Surveys: The Tailored Design Method (4 ${ }^{\text {th }}$ Ed.). Wiley.

Dimanche, F., and D. Samdahl. 1994. "Leisure as Symbolic Consumption: A Conceptualization and Prospectus for Future Research. Leisure Sciences, 16(2): 119-129. 
Dunlap, R.E., K.D. Van Liere, A.G. Mertig, and R.E. Jones. 2000. "New Trends in Measuring Environmental Attitudes: Measuring Endorsement of the New Ecological Paradigm: A Revised NEP Scale." Journal of Social Issues, 56(3), 425-442.

Eid, R., G. Agag, and Y.M. Shehawy. 2020. “Understanding Guests' Intention to Visit Green Hotels.” Journal of Hospitality \& Tourism Research, https://doi.org/10.1177/1096348020947800

Eijgelaar, E., C. Thaper, and P. Peeters. 2010. "Antarctic Cruise Tourism: The Paradoxes of Ambassadorship, 'Last Chance Tourism' and Greenhouse Gas Emissions.” Journal of Sustainable Tourism, 18(3): 337354.

Erul, E., K.M. Woosnam, and W.A. McIntosh. 2020. “Considering Emotional Solidarity and the Theory of Planned Behavior in Explaining Behavioral Intentions to Support Tourism Development. Journal of Sustainable Tourism, 28(8): 1158-1173.

Fisher, D., and E.J. Stewart. 2017. "Tourism, Time, and the Last Chance." Tourism Analysis, 22(4): 511-521.

Fornell, C., and D.F. Larcker. 1981. "Evaluating Structural Equation Models with Unobservable Variables and Measurement Error." Journal of Marketing Research 18(1): 39-50.

Groulx, M., C. Lemieux, J. Dawson, E. Stewart, and O. Yudina. 2016. "Motivations to Engage in Last Chance Tourism in the Churchill Wildlife Management Area and Wapusk National Park: The Role of Place Identity and Nature Relatedness." Journal of Sustainable Tourism, 24(11): 1523-1540.

Hair, J.F., B.J. Babin, R.E. Anderson, and W.C. Black. 2019. Multivariate Data Analysis (8 ${ }^{\text {th }}$ Ed.). Independence, Kentucky: Cengage.

Han, H. 2015. "Travelers' Pro-environmental Behavior in a Green Lodging Context: Converging Value-BeliefNorm Theory and the Theory of Planned Behavior." Tourism Management, 47, 164-177.

Han, H., and J. Hwang. 2017. "What Motivates Delegates' Conservation Behaviors while Attending a Convention?" Journal of Travel \& Tourism Marketing, 34(1): 82-98.

Han, H., J. Hwang, J. and M.J. Lee 2017. "The Value-Belief-Emotion-Norm Model: Investigating Customers' Eco-friendly Behavior.” Journal of Travel \& Tourism Marketing, 34(5): 590-607.

Han, H., L.T.J. Hsu, and C. Sheu. 2010. "Application of the Theory of Planned Behavior to Green Hotel Choice: Testing the Effect of Environmental Friendly Activities.” Tourism Management, 31(3): 325334.

Han, H., H.G. Olya, S.B. Cho, and W. Kim. 2018. "Understanding Museum Vacationers' Eco-friendly Decision-making Process: Strengthening the VBN Framework. Journal of Sustainable Tourism, 26(6): 855-872.

Han, H., and S.S. Hyun. 2017. "Drivers of Customer Decision to Visit an Environmentally Responsible Museum: Merging the Theory of Planned Behavior and Norm Activation Theory." Journal of Travel \& Tourism Marketing, 34(9): 1155-1168.

Hu, L.T., and P.M. Bentler. 1999. "Cutoff Criteria for Fit Indexes in Covariance Structure Analysis: Conventional Criteria Versus New Alternatives. Structural Equation Modeling: A Multidisciplinary Journal, 6(1): 1-55.

Hindley, A., and X. Font. 2018. "Values and Motivations in Tourist Perceptions of Last-chance Tourism." Tourism and Hospitality Research, 18(1): 3-14.

Jansson, J., A. Marell, and A. Nordlund. 2010. "Green Consumer Behavior: Determinants of Curtailment and Eco-innovation Adoption.” Journal of Consumer Marketing, 27(4): 358-370.

Joo, D., and K.M. Woosnam. 2020. "Measuring Tourists' Emotional Solidarity with one another-A Modification of the Emotional Solidarity Scale." Journal of Travel Research, 59(7): 1186-1203.

Jordan, E.J., B.B. Boley, W. Knollenberg, and C. Kline. 2018. "Predictors of Intention to Travel to Cuba across Three Time Horizons: An Application of the Theory of Planned Behavior. Journal of Travel Research, 57(7): 981-993. 
Jordan, P. J., and A.C. Troth. 2020. "Common Method Bias in Applied Settings: The Dilemma of Researching in Organizations." Australian Journal of Management 45(1): 3-14

Krüger, O. 2005. "The Role of Ecotourism in Conservation: Panacea or Pandora's Box?. Biodiversity \& Conservation, 14(3): 579-600.

Landon, A.C., K.M. Woosnam, and B.B. Boley. 2018. "Modeling the Psychological Antecedents to Tourists' Pro-sustainable Behaviors: An Application of the Value-Belief-Norm Model." Journal of Sustainable Tourism, 26(6): 957-972.

Lee, T.H., and F.H. Jan. 2018. "Ecotourism Behavior of Nature-based Tourists: An Integrative Framework. Journal of Travel Research, 57(6): 792-810.

Lemelin, H., J. Dawson, and E.J. Stewart. (Eds.). 2013. Last Chance Tourism: Adapting Tourism Opportunities in a Changing World. Routledge

Lemelin, H., J. Dawson, E.J. Stewart, P. Maher, and M. Lueck. 2010. "Last-chance Tourism: The Boom, Doom, and Gloom of Visiting Vanishing Destinations." Current Issues in Tourism, 13(5): 477-493.

Lemelin, H., and P. Whipp. 2019. "Last Chance Tourism: A Decade in Review." In D. Timothy (Ed.) Handbook of Globalisation and Tourism (pp. 316-322). Northampton, MA: Edward Elgar Publishing.

Lemieux, C.J., M. Groulx, E. Halpenny, H. Stager, J. Dawson, E.J. Stewart, G.T. Hvenegaard. 2018. "The end of the Ice Age?" Disappearing World Heritage and the Climate Change Communication Imperative. Environmental Communication, 12(5): 653-671.

Liggett, D., A. McIntosh, A. Thompson, B. Storey, and N. Gilbert. 2010. "Stakeholder Perspectives on the Governance of Antarctic Cruise Tourism." In Lück, M., Maher, P., and Stewart, E.J. (Eds) Cruise Tourism in Polar Regions: Promoting Environmental and Social Sustainability (pp. 167-203). New York: Earthscan.

López-Mosquera, N., and M. Sánchez. 2012. "Theory of Planned Behavior and the Value-Belief-Norm Theory Explaining Willingness to Pay for a Suburban Park. Journal of Environmental Management, 113, 251262.

Megeirhi, H.A., K.M. Woosnam, M.A. Ribeiro, H. Ramkissoon, and T.J. Denley. 2020. "Employing a ValueBelief-Norm Framework to Gauge Carthage Residents' Intentions to Support Sustainable Cultural Heritage Tourism.” Journal of Sustainable Tourism, 28(9): 1351-1370.

Mehran, J., and H.G. Olya. 2020. "Canal Boat Tourism: Application of Complexity Theory." Journal of Retailing and Consumer Services, 53, https://doi.org/10.1016/j.jretconser.2019.101954

Meng, B., B.L. Chua, H.B. Ryu, and H. Han. 2020. "Volunteer Tourism (VT) Traveler Behavior: Merging Norm Activation Model and Theory of Planned Behavior. Journal of Sustainable Tourism, 28(12): 1947-1969.

Moon, H., and H. Han. 2018. "Destination Attributes Influencing Chinese Travelers' Perceptions of Experience Quality and Intentions for Island Tourism: A Case of Jeju Island.” Tourism Management Perspectives, 28, 71-82.

Olsen, D.H., R.L. Koster, and N. Youroukos. 2012. "Last Chance Tourism? Public Sector Views of Marketing Endangered Tourism Destinations in North America." In R.H. Lemelin, J. Dawson, and E.J. Stewart (Eds.), Last Chance Tourism: Adapting Tourism Opportunities in a Changing World. (pp.105-116). New York: Routledge.

Piggott-McKellar, A.E., and K.E. McNamara. 2017. "Last Chance Tourism and the Great Barrier Reef." Journal of Sustainable Tourism, 25(3): 397-415.

Podsakoff, P.M., S.B. MacKenzie, J-Y. Lee, and N.P. Podsakoff. 2003. "Common Method Biases in Behavioral Research: A Critical Review of the Literature and Recommended Remedies." Journal of Applied Psychology, 88(5): 879-903. 
Pukka Travels. 2020. "Tesla Hiking." Retrieved on November 20, 2020 from https://www.pukkatravels.com/zzz-archive-tour/tesla-x-fjord-hiking$1599575861074 \times 386370324302575100$

Raymond, C.M., G. Brown, G.M. Robinson. 2011. "The Influence of Place Attachment, and Moral and Normative Concerns on the Conservation of Native Vegetation: A Test of two Behavioural Models." Journal of Environmental Psychology, 31(4): 323-335.

Schwartz, S.H. 1977. "Normative Influences on Altruism." Advances in Experimental Social Psychology, 10(1): 221-279.

Schwartz, S.H., and W. Bilsky. 1987. "Toward a Universal Psychological Structure of Human Values." Journal of Personality and Social Psychology, 53(3): 550.

See, G.T., and Y.N. Goh. 2019. "Tourists' Intention to Visit Heritage Hotels at George Town World Heritage Site." Journal of Heritage Tourism, 14(1): 33-48.

Sharma, R., and A. Gupta. 2020. "Pro-environmental Behaviour among Tourists Visiting National Parks: Application of Value-Belief-Norm Theory in an Emerging Economy Context." Asia Pacific Journal of Tourism Research, 25(8): 829-840.

Steg, L., and J. Groot. 2010. "Explaining Prosocial Intentions: Testing Causal Relationships in the Norm Activation Model." British Journal of Social Psychology, 49(4): 725-743.

Stern, P.C. 2000. "Toward a Coherent Theory of Environmentally Significant Behavior.” Journal of Social Issues, 56(3): 407-424.

Stern, P.C., T. Dietz, and G.A. Guagnano. 1995. "The New Ecological Paradigm in Social-Psychological Context." Environment and Behavior, 27(6): 723-743.

Stern, P.C., T. Dietz, T. Abel, G.A. Guagnano, and L. Kalof. 1999. "A Value-Belief-Norm Theory of Support for Social Movements: The Case of Environmentalism." Human Ecology Review, 6(2): 81-97.

Stoner, K.R., M.A. Tarrant, L. Perry, L. Stoner, S. Wearing, and K. Lyons. 2014. "Global Citizenship as a Learning Outcome of Educational Travel." Journal of Teaching in Travel \& Tourism, 14(2): 149-163.

Suess, C., K.M. Woosnam, and E. Erul. 2020. "Stranger-danger? Understanding the Moderating Effects of Children in the Household on Non-hosting Residents' Emotional Solidarity with Airbnb Visitors, Feeling Safe, and Support for Airbnb." Tourism Management, 77, https://doi.org/10.1016/j.tourman.2019.103952

Suess, C., K.M. Woosnam, M. Mody, T. Dogru, and E. Sirakaya Turk. 2020. “Understanding how Residents' Emotional Solidarity with Airbnb Visitors Influences Perceptions of their Impact on a Community: The Moderating Role of Prior Experience Staying at an Airbnb. Journal of Travel Research, https://doi.org/10.1177/0047287520921234

Tasci, A. D. 2017. "Consumer Demand for Sustainability Benchmarks in Tourism and Hospitality." Tourism Review, 72(4): 375-381.

Tasci, A.D., and A. Milman. 2019. "Exploring Experiential Consumption Dimensions in the Theme Park Context." Current Issues in Tourism, 22(7): 853-876.

Tölkes, C. 2020. "The Role of Sustainability Communication in the Attitude-behaviour Gap of Sustainable Tourism." Tourism and Hospitality Research, 20(1): 117-128.

van Riper, C.J., and G.T. Kyle. 2014. "Understanding the Internal Processes of Behavioral Engagement in a National Park: A Latent Variable Path Analysis of the Value-Belief-Norm Theory." Journal of Environmental Psychology, 38, 288-297.

Vehovar, V., V. Toepoel, and S. Steinmetz. 2016. "Non-probability Sampling." In The Sage Handbook of Survey Methods (pp. 329-345). Thousand Oaks, CA: Sage.

Visit Tromso. 2020. "Travel Green." Retrieved on November 20, 2020 from https://www.visittromso.no/sustainable/green-travel 
Zhang, Y., S. Cole, P. Ricci, and J. Gao. 2019. "Context-based Leisure Travel Facilitation among People with Mobility Challenges: A Self-determination Theory Approach.” Journal of Travel Research, 58(1): 4262.

Zhang, K., Y. Hou, and G. Li. 2020. "Threat of Infectious Disease during an Outbreak: Influence on Tourists' Emotional Responses to Disadvantaged Price Inequality.” Annals of Tourism Research, 84, 102993. 
Table 2. Measurement model results

\begin{tabular}{|c|c|c|c|c|c|}
\hline Factor and corresponding items & $M(\mathrm{SD})$ & $\beta$ & $t$ & $\mathrm{CR}$ & AVE \\
\hline Egoistic values $^{\text {a }}$ & 3.93(1.34) & & & 0.79 & 0.56 \\
\hline Social power: Control over others, dominance & $3.15(1.58)$ & 0.84 & $\dagger$ & & \\
\hline Authority: The right to lead or command & $4.06(1.71)$ & 0.78 & $12.73^{* * *}$ & & \\
\hline Influence: Having an impact on people and events & $4.56(1.52)$ & 0.60 & $10.97^{* * *}$ & & \\
\hline Altruistic values ${ }^{\mathbf{a}}$ & $5.80(1.11)$ & & & 0.82 & 0.61 \\
\hline Equality: Equal opportunity for all & $5.88(1.32)$ & 0.85 & $14.88^{* * *}$ & & \\
\hline Social justice: Correcting injustice, care for others & $5.70(1.39)$ & 0.77 & $14.04^{* * *}$ & & \\
\hline A world at peace: A world free of war and conflict & $5.82(1.19)$ & 0.72 & $\dagger$ & & \\
\hline Biospheric values ${ }^{\mathrm{a}}$ & $5.58(1.16)$ & & & 0.85 & 0.66 \\
\hline Protecting the environment: Preserving nature & $5.71(1.27)$ & 0.95 & $19.28^{* * *}$ & & \\
\hline Unity with nature: Fitting into nature & $5.44(1.39)$ & 0.77 & $\dagger$ & & \\
\hline A world of beauty: Beauty of nature and the arts & $5.59(1.30)$ & 0.69 & $14.41^{* * *}$ & & \\
\hline Environmental worldview (New Ecological Paradigm) ${ }^{\mathbf{b}}$ & $5.41(1.15)$ & & & 0.80 & 0.50 \\
\hline When humans interfere with nature, it often produces disastrous results & $5.52(1.37)$ & 0.78 & $\dagger$ & & \\
\hline The balance of nature is very delicate and easily upset & $5.47(1.39)$ & 0.72 & $14.18^{* * *}$ & & \\
\hline Plants and animals have as much right to exist as humans & $5.80(1.37)$ & 0.70 & $13.52^{* * *}$ & & \\
\hline The earth is like a spaceship with very limited room and resources & $4.86(1.70)$ & 0.62 & $11.81^{* * *}$ & & \\
\hline Awareness of consequences ${ }^{b}$ & $5.21(1.19)$ & & & 0.89 & 0.61 \\
\hline Pollution of local environments & $5.45(1.36)$ & 0.86 & $\dagger$ & & \\
\hline Waste (trash, sewage, etc.) coming from tourists & $5.20(1.45)$ & 0.79 & $18.55^{* * *}$ & & \\
\hline Destruction of native species' habitats & $5.20(1.45)$ & 0.78 & $18.30^{* * *}$ & & \\
\hline Carbon emissions from transportation (airplanes, cars, etc.) & $5.37(1.40)$ & 0.74 & $16.77^{* * *}$ & & \\
\hline Water scarcity and overuse & $5.20(1.45)$ & 0.73 & $16.62^{* * *}$ & & \\
\hline Ascription of responsibility ${ }^{c}$ & $5.54(1.07)$ & & & 0.85 & 0.65 \\
\hline Minimizing my impacts on the environment is in part my responsibility & $5.75(1.15)$ & 0.88 & $21.56^{* * *}$ & & \\
\hline It is my responsibility to minimize my impacts on the environment as a tourist & $5.75(1.11)$ & 0.83 & $\dagger$ & & \\
\hline I feel jointly responsible for tourism impacts on the environment & $5.12(1.44)$ & 0.70 & $15.62^{* * *}$ & & \\
\hline Personal norms ${ }^{\mathrm{c}}$ & $5.85(0.96)$ & & & 0.92 & 0.69 \\
\hline I am obligated to do my part to reduce my impact on the environment as a tourist & $5.75(1.08)$ & 0.86 & $21.26^{* * *}$ & & \\
\hline People like me should do what they can to minimize their impact on the environment when travelling & $5.85(1.09)$ & 0.84 & $23.89^{* * *}$ & & \\
\hline Minimizing my impact on the environment is the right thing to do & $6.07(1.06)$ & 0.84 & $\dagger$ & & \\
\hline As a tourist, I feel morally obligated to do whatever I can to minimize my environmental impact & $5.55(1.22)$ & 0.83 & $18.09^{* * *}$ & & \\
\hline I would feel guilty if I were responsible for damage to the environment as a tourist & $6.04(1.10)$ & 0.77 & $18.20^{* * *}$ & & \\
\hline
\end{tabular}


Travelling to an LCT destination would be rewarding

$4.82(1.54)$

Travelling to an LCT destination would be enjoyable

Travelling to an LCT destination would be pleasant

\section{Negative attitudes about LCT}

$3.35(1.73)$

Travelling to an LCT destination would be uncomfortable

$3.35(1.73)$

Subjective norms ${ }^{\mathrm{c}}$

Most people who are important to me expect me to travel to LCT destinations

Most people who are important to me encourage me to travel to LCT destinations

3.68(1.54)

$4.41(1.48)$

$3.60(1.59)$

Most people who are important to me think I should visit LCT destinations

$3.51(1.60)$

Most people who are important to me would visit LCT destinations themselves

3.94(1.49)

$5.36(1.43)$

\section{Perceived behavioral control}

It is mostly up to me whether or not I travel to an LCT destination in the near future

$5.22(1.42)$

Whether or not to a visit an LCT destination in the near future is completely up to me

$5.32(1.37)$

$5.25(1.35)$

If I wanted to travel to an LCT destination in the near future, I could

$5.25(1.35)$
$5.24(1.48)$

I have the complete control over visiting an LCT destination in the near future

$5.79(1.53)$

a Items measured on scale of 1-7 ( 1 = not at all important; $7=$ very important $)$

${ }^{\mathrm{b}}$ Items measured on scale of $1-7(1=$ not at all a problem; $7=$ a very serious problem $)$

${ }^{\mathrm{c}}$ Items measured on scale of 1-7 (1 = strongly disagree; 7 = strongly agree $)$

Note: $M(\mathrm{SD})$ : mean (standard deviation); $\beta$ : standardized factor loading; $t$ : value of corresponding factor loading; CR: composite reliability; AVE: Average variance extracted; ${ }^{* * *}$ indicates significant at $p<0.001$ level.

${ }^{\dagger}$ loading fixed to 1 . 
